\title{
Hey, Hey, Hey-Listen to What I Gotta Say: Songs Elevate Youth Voice in Alberta Wildfire Disaster Recovery
}

\author{
Tamara Plush, Robin Cox
}

\begin{abstract}
Music pulses emotion in its lyrics, its tune, and in the creative process. A song can move people to dance, to reflect, and — often — to act. For an artist, a song's creation can also reveal and clarify one's own emotions. When people listen, a song can legitimize that the artists have something valuable to say-especially when the artists are youth who believe their ideas need a wider audience. This article talks about the power of song for youth recovery post-disaster in the context of the 2016 Fort McMurray wildfire disaster in Alberta, Canada. It highlights the use of music in a community-engaged research project that aimed to understand and amplify youth ideas for improving their community. The article draws on the value of Youth-Adult Partnerships, where eight youth worked with a professional recording studio in the wildfire-affected community to produce original songs for a youth-centric social media campaign. Focusing on the youths' songs and personal experiences of their development, the article offers ways forward for wildfire recovery through processes that strengthen youth voice and wellbeing. The community-engaged research process underscores the power of music creation as an empowering method for enhancing youth engagement and reveals youths' insights through their musical reflections on their priorities for a resilient community after disaster.
\end{abstract}

KEYWORDS Music creation, community-engaged research, youth voice, disaster recovery

In downtown Fort McMurray, Hannah, age 15 (Figure 1), strums her guitar to tune it, and then nods; she's ready to record. The song producer sets the levels, nods back, and she belts the chorus of Hey, Hey, Hey ${ }^{1}$ into the microphone: "Hey, hey, hey. Listen to what I gotta say. I'm not silent; I'm just not being heard. Things can be better here I'm sure.” Hannah's song lyrics give voice to ideas she has for her community to build back better and stronger after the 2016 Horse River wildfire (a.k.a., the FortMcMurray wildfire) devastated her town in Alberta, Canada. Hannah created her song as part of the Youth Voices Rising (YVR): Recovery and Resilience in Wood Buffalo ${ }^{2}$ research project facilitated by the ResiliencebyDesign Research Innovation Lab at Royal Roads University. It included a social media campaign named \#YouthVoicesWB that featured creative content created by youth.

\footnotetext{
${ }^{1}$ www.thedistrictstudio.ca/youthvoiceswb.html

2 www.resiliencebydesign.com/yvr
} 


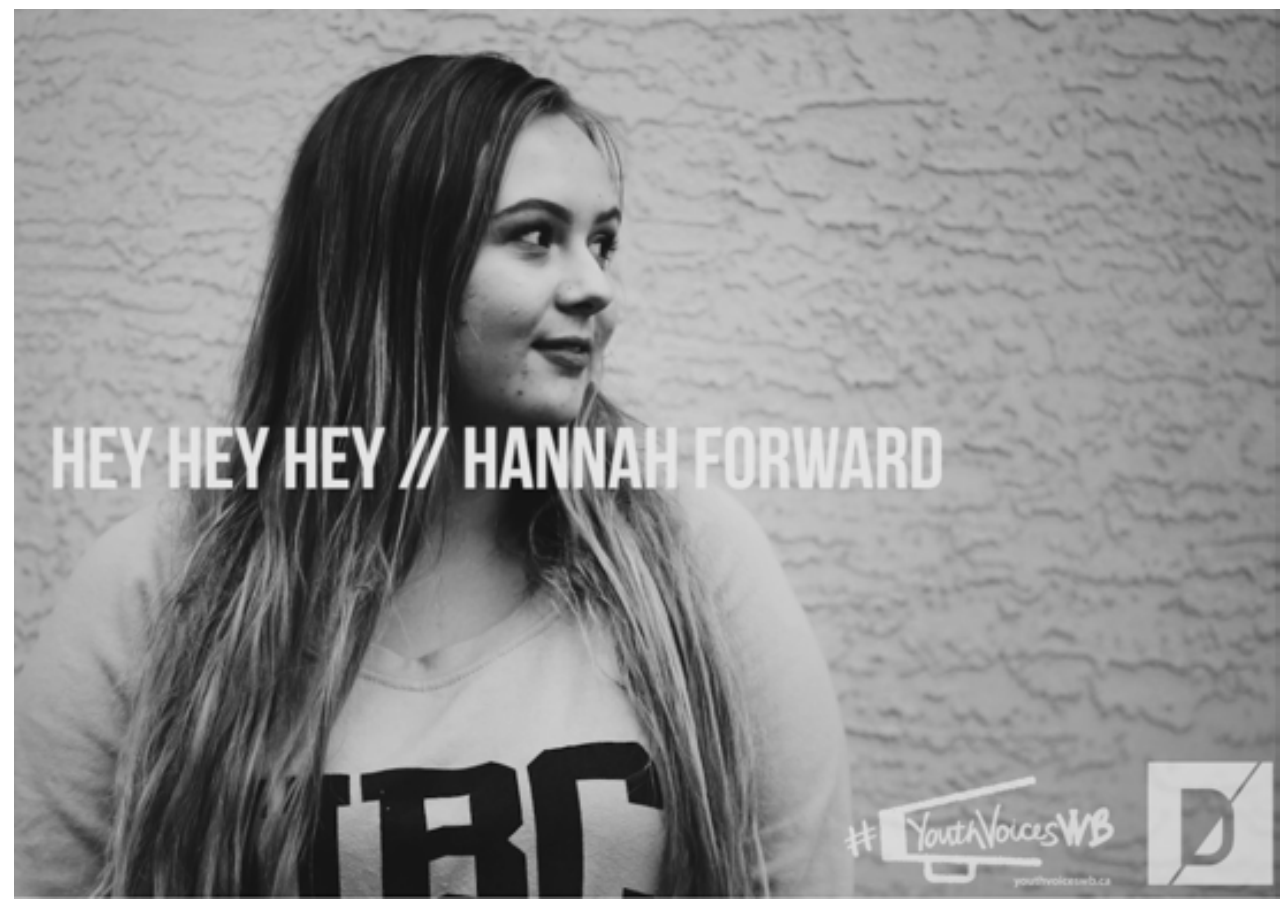

Figure 1. Hannah

$\mathrm{RbD}$ Lab researchers from the YVR project issued a call to youth ${ }^{3}$ aged 14 to 24 for their creative responses to the question: "What would you do to make your community better?" \#YouthVoicesWB ${ }^{4}$ was an integral part of a two-year community-engaged research process that worked with local youth in the campaign's naming, development, content creation, and execution.

As both research and a campaign, \#YouthVoiceWB aimed to not only generate knowledge through supporting arts-based opportunities and resources for young people to create their own messages (Barone \& Eisner, 2011; Leavy, 2015). It also supported activities with youth that could strengthen, amplify, and legitimize their concerns as active participants in the disaster recovery; actions that can foster greater youth agency and resilience (Fothergill \& Peek, 2015; Macpherson, Hart, \& Heaver, 2016; Seballos \& Tanner, 2011).

This intentional connection between university research and the wildfire-affected community (Hall, Tandon, \& Tremblay, 2015) served as a catalyst to both advance knowledge and strengthen local capacity for supporting and mobilizing Youth-Adult Partnerships (Y-APs) (Camino, 2000). It also led to diverse expressions of youth voice through creative arts, supported by multiple local organizations participating in the research project.

Creating opportunities for youth to build new connections and a sense of agency is at the

\footnotetext{
${ }^{3}$ The project used the United Nations universal definition of youth as age 14-24.

${ }^{4}$ See www.facebook.com/YouthVoicesWB, www.instagram.com/youthvoiceswb, and https://twitter.com/YouthVoicesWB
} 
heart of creative arts-based activities (Flicker et al., 2016; Conrad \& Campbell, 2008). When integrated into research, they can be used to deepen conversations and meaning making. They can also enhance and amplify the voice of participants and generate knowledge and actions with potential to influence decisions and policies (Peek, Tobin-Gurley, Cox, Scannell, Fletcher, \& Heykoop, 2016). In this way, art creation within a research process produces generative, impactful, and useful data and knowledge mobilization tools. Such approaches can also act as interventions for and with young people (D'Amico et al., 2016; Walls, Deane, \& O'Connor, 2016).

This was apparent in the high level of participation in the \#YouthVoicesWB campaign. In addition to the youth songs described in this article, more than 350 youth across the region responded to the research question through various creative means from photography to poetry to podcasts and sticky notes. The researchers analyzed their answers, and 20 additional interviews with youth participants, to identify five key youth priorities for improving the disaster-affected region: "transportation, health and wellbeing, education, volunteerism, and participation and activities" (ResiliencebyDesign Lab, 2018, p. 13), as explained in the Youth Voice \& Vision in Wood Buffalo report. This article will share how one of the activities-creating songs through a local Y-AP_operated to the benefit of youth for recovery within the larger communityengaged research process, especially in relation to enhancing youth voice and wellbeing. It will also include insight from the eight youth who created seven original songs (six soloists and one duo) for the \#YouthVoicesWB campaign (Hannah, Shekinah, Willi, Genoveve, OG, Kyler, Chris, and Robyn ${ }^{5}$ ). The youth also participated in follow-up interviews and videos about these songs, which are also highlighted. The song lyrics and quotes from the interviews and videos provide insight into the meaning-making process and the impact of producing and sharing their songs on the participating youth. They also demonstrate the range of their concerns and ideas sparked by the campaign question and by the wildfire experience itself.

For instance, multiple songs reflected young peoples' sense of hope and the potential for a stronger sense of community to emerge from the wildfire experience. This is heard in the lyrics by Shekinah, age 15, in her song Recovery, "We're building from the ground up/Hand in hand here we stand" (see Figure 2); and in Hannah's words "Change is what I need to see." Willi and Genoveve, both age 20, link their song to hope in explaining to community members that "It's time to return wandering souls." The song Change ${ }^{6}$ also reflects the young peoples' experience of a deepened connection to the natural environment that arose because of the wildfire's visible impacts on their environment, as this comment by Willi illustrates:

Taking a walk outside, you see the burnt trees but you also see the green coming through...I tend to connect to nature a lot, so even the scenery and the nature around it have this hopeful bit waiting to come.

\footnotetext{
${ }^{5}$ The RbD Lab would like to thank the youth (and their parents and guardians for those under age 18) for being part of the Youth Voices Rising project, and providing their permission to use their names, insight, songs, and photos for academic scholarship. We also thank them for their beautiful songs in the \#YouthVoicesWB campaign.

6 www.thedistrictstudio.ca/youthvoiceswb.html
} 


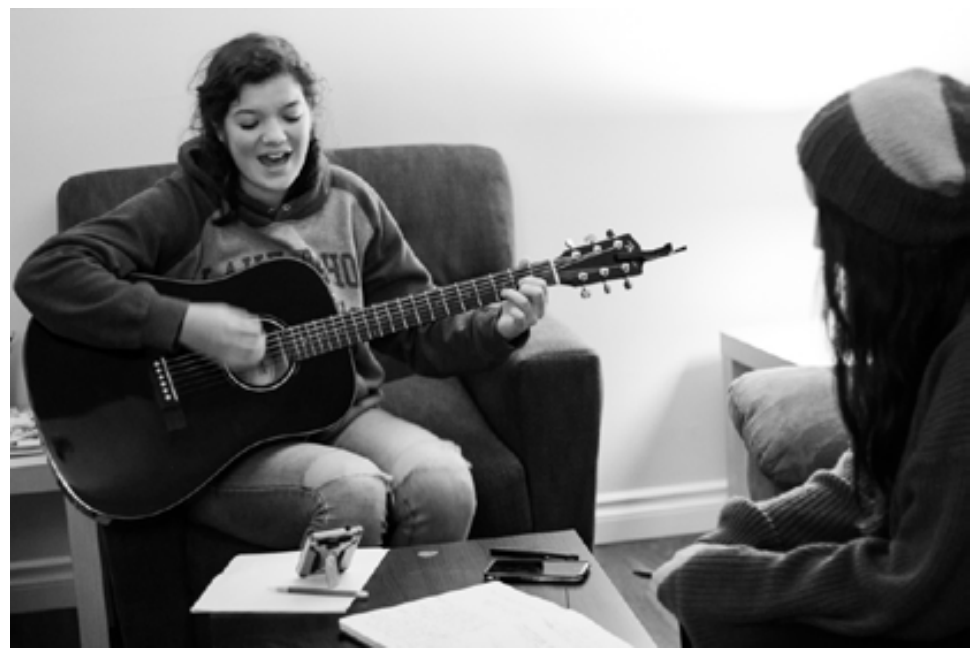

Figure 2. Shekinah

The idea for the song Change started with a stroll through a nearby forest and paints a picture of their experience of walking in the burnt landscape:

The trees stand bare in the warm August air; black bark bears witness to the flames. The flowers, they're growing; all the while full-knowin' it'll be a while before the forest looks the same. But we'll press on. Come together, join in the song. 'Cause there's strength in waiting. Together we're making a change. Yeah, there's gonna be change.

These examples show that youth have strong connections to their community and a desire for positive change after disaster strikes. They exemplify ideas that participation in creative arts can help cultivate empathy (Malin, 2015), and contributes to optimism and positive youth development (Elpus, 2013), subjective wellbeing (Wheatley \& Bickerton, 2017), and the development of critical thinking skills amongst other things. As discussed in the following sections, the songs also illustrate how using creative arts in community-engaged research not only generates knowledge, but also can support youth in their own recovery.

\section{Validating and Legitimizing Youth Voice}

Research shows that young people's active involvement in their own recovery helps them to understand and enact their rights as citizens able to determine their own future (Cox, Hill, Plush, Heykoop, \& Tremblay, 2018; Fletcher, Cox, Scannell, Heykoop, Tobin-Gurley, \& Peek, 2016). Youth engagement also supports the capacity of communities, and in building current and future leaders, entrepreneurs, and innovators (Back, Cameron, \& Tanner, 2009; Ho, Clarke, \& Dougherty, 2015). Engaging youth, however, is not always as straight-forward as inviting them to meetings or focus groups; especially for reaching youth who may not be the first to step forward to participate (Cox et al., 2018). This is why the YVR project focused on 
creative arts as a youth-friendly engagement method for both understanding youth concerns and strengthening their capacity as citizens with valuable ideas to share in the context of rebuilding after disaster (Haynes \& Tanner, 2015).

Such contribution is illustrated in Hannah's song Hey, Hey, Hey where she shares her unique ideas for a more resilient community including the need for adult mentorship, street cafes, bike lanes, and opportunities for artistic youth. She points out issues she feels strongly about in her song: "There's lots here that's just not right. Downtown suburbia has been a plight. Neighbourhoods silent; streets are bare; nothing is walkable; destinations rare." Her lyrics also emphasize a sense of shared responsibility for finding solutions to these problems, singing: "I work to change this town of ours to make it better; to make us proud."

Despite feeling distant from policymakers, research shows that the idea of influencing power is important to youth-especially on decisions that directly affect them and their families (Grauenkaer \& Tufte, 2018; Haynes \& Tanner, 2015; Plush 2009). Illustratively in a video interview about her song, Hannah explains the challenges she and other youth find in being listened to and having equal representation in decisions in her community:

Young people can't vote, but they still have opinions on things in the community. Because they don't have the power with voting and stuff, it's really hard for them to speak their voice. So, it's really important that we start bringing more awareness to that and motivate people to create change in the community.

For the \#YouthVoicesWB campaign, supporting youth to contribute their creative ideas through social media was informed by research on the positive role of youth empowerment and engagement through arts-based methods on youth development and resilience. For instance, youth empowerment has been identified as a mediator of positive developmental outcomes and influential in reducing marginalization (Christens \& Peterson, 2012; Fernandez $\&$ Shaw, 2013). It also plays a role in strengthening youth resilience in the face of stress and change (Ungar, 2012). From this perspective, meaningful and authentic youth engagement in issues of concern to them can contribute not only to the greater civic engagement but also to the individual wellbeing of youth (Cox et al. 2018). Including youth perspectives in disaster recovery decision making also helps to ensure their unique perspectives are included, as called for in the Sendai Framework for Disaster Risk Reduction 2015-2030 (UNISDR, 2015).

Local government partners can also provide opportunities to strengthen the legitimacy of youth voice and spark action. For instance, RbD Lab researchers ran the \#YouthVoicesWB campaign specifically during the 2017 Regional Municipality of Wood Buffalo (RMWB) mayoral election cycle. The campaign also included "Mayoral Mondays" in its Instagram and Facebook posts to feature interviews with the Mayoral candidates ${ }^{7}$ on their opinions on meaningful youth engagement. This timing reflected the desire to not only amplify youth voice, but to cultivate possibilities for meaningful and responsive listening to occur between decision makers and youth with legitimate concerns and innovative solutions (Dutta, 2014;

${ }^{7}$ www.youtube.com/watch?v=dh--6Jzsa1M 
Plush, 2016). Used in this way, the campaign served as a catalyst to raise awareness and build youth capacity on one hand; and on the other to support youth-driven advocacy efforts that put young people in a better position to influence policies and decisions connected to the wildfire recovery (Peek et al., 2016; Plush, 2015).

For instance, the researchers were able to leverage the relationship they had built during the campaign to invite the newly elected Mayor, Don Scott, to a youth talent showcase of \#YouthVoicesWB artists. This provided an opportunity for youth to see and hear that their ideas have weight in community decision making. During this event, Mayor Scott (Nov. 10, 2017) spoke directly to the importance of listening to young people:

I want you to believe that what you think and say makes a difference... If you don't think your voice matters; that is totally incorrect. Your voice matters... But unless you're telling us what you are experiencing, we are not going to know what to make better... So, believe in yourself. I just want you to know that you'll have a voice in the Mayor going forward. We want to make this community better not just for us, but for all of you.

The young performers noticed and remembered his message months after the event, and even offered advice to improve the connection, as OG described:

It's not that we don't want to express our ideas and whatever. There are not the right outlets for us to do it. When the Mayor was talking at the Youth Voices thing he said that he has his phone number public and he has his email public, and we can message him directly. I thought that was cool 'cause, see 'I have a problem with how things are going, and I can tell someone to actually fix them,' right? I think that making outlets useful to us [to share ideas] — not a Dropbox that never gets read...something that we can express ourselves and make it as if it was an actual thing that can actually change.

The campaign also highlighted challenges in providing space for authentic, uncensored youth voice. For example, concerns were raised about how the line in Kyler's song, "Fuck the rules. I ain't ever been complying," might be received by youth, parents, and community members following the online campaign. The words are a powerful statement that directly connects with and reflects Kyler's life experiences. Rather than censor the line, the researchers and community partner approached Kyler as a professional artist. They explained the dilemma of wanting to give him free reign to express himself and the challenges that might ensue from posting the song on a site that included a younger audience. Negotiation and respect were key to legitimizing Kyler's voice as he himself had talked in a video interview about how people might respond to his song:

I'd like some positive feedback but there are going to be those few that are going to be like 'man, he's talking about going to jail and stuff like that,' but I'm not trying to hide who I am. This stuff really happened to me. I don't want people to judge me.

${ }^{8}$ www.youtube.com/watch?v $=\mathrm{a} 5 \mathrm{tW}$ wS8JfzI 


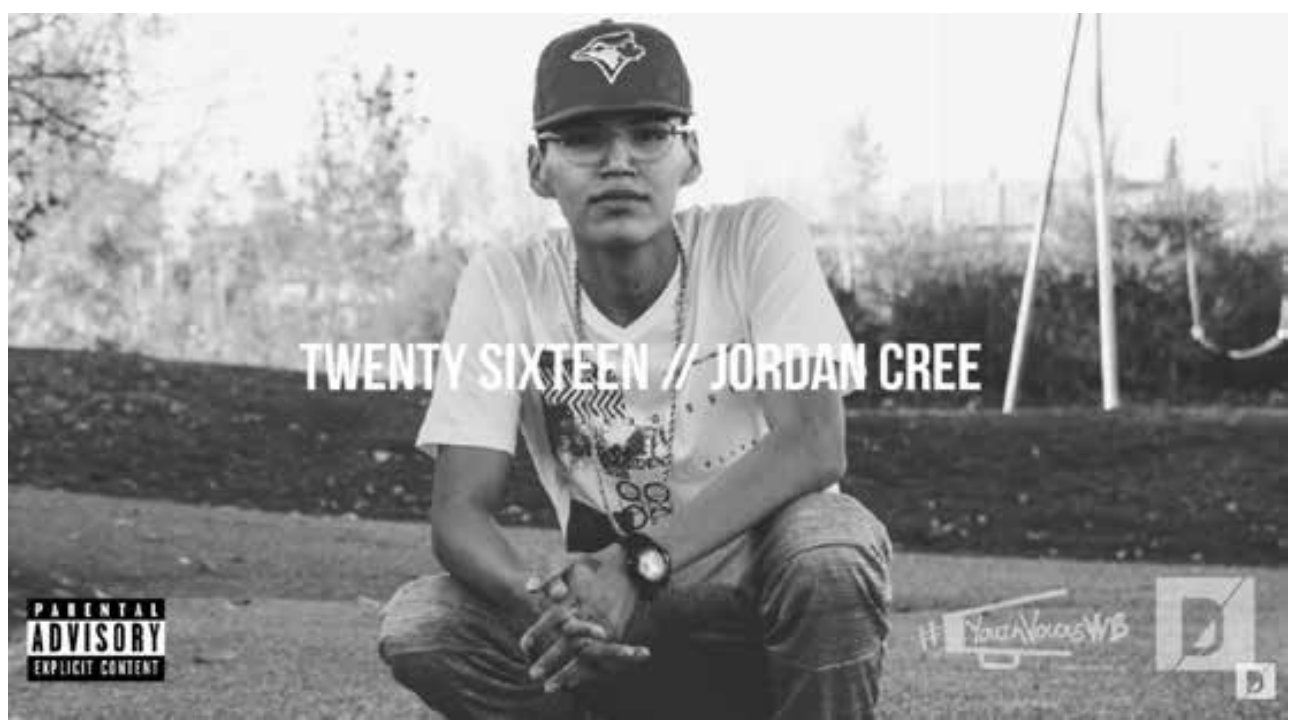

Figure 3. Kyler

Rather than removing or censoring the lyric, the researchers and local recording studio team worked with Kyler to add a message warning of explicit content, thereby honouring Kyler's authentic voice and story (see Figure 3). This is an example of how arts-based activities can result in creative knowledge products with the potential to be controversial. However, honouring and supporting the integrity of what young people share-as well as positioning the research alongside local Youth-Adult Partnerships-is important to ensure youth will be validated and legitimized.

\section{Strengthening Youth Wellbeing}

Promoting youth-generated music within the project also recognized its value in supporting youth wellbeing (Davis, 2010; Papinczak, Dingle, Stoyanov, Hides, \& Zelenko, 2015). As an example, in his song Happiness, ${ }^{9}$ Chris, age 18, asks: "How do you know where to go when you feel so low?" and ends with the lyrics, "That when I'm walking, I will be alright. And when I'm broken, you will be by my side. And out of nowhere, I will find you tonight. Yeah, I believe." After recording the song, Chris made the link between his song's message, the wildfire, and depression. He explained he would like the song to connect to people struggling to cope following the fire; and help them find happiness. He highlights this in the song's lyrics, "You just need to hold on; you need to keep going no matter how tough things are." He explains that the song ties into who he is now and to the hope he himself has taken away from the experience:

With the wildfire people lost stuff. Personally, I lost my house and the things that were

${ }^{9}$ www.thedistrictstudio.ca/youthvoiceswb.html 
in there. I mean everything is fine now, but still. And with that, with the song and relevance to the wildfire and people having to go through that, I think it would help people who are going through stuff... It's a reflection of what people needed to do just to keep on going. And what people needed really is happiness, to have hope and faith, and everything's going to be alright.

Considerable evidence shows that youth can be at greater risk for developing symptoms of anxiety, depression, and post-traumatic stress disorder (PTSD) following natural disasters (Fothergill \& Peek, 2015; Peek, Abramson, Cox, Fothergill, \& Tobin 2018). Resource allocation for youth-centric mental health, however, is often overlooked or underfunded (Blanchet-Cohen \& Nelems, 2013). Specific programs that allow youth to connect and discuss their disaster experiences can aid in reducing such symptoms, as well as guide children and youth in healing and capacity-building (Powell \& Holleran-Steiker, 2017). Accordingly, multiple strategies are required to address youth wellbeing after a disaster event, including the use of arts (Fletcher et al., 2016; Peek et al., 2016). This link between music creation and wellbeing is evidenced in how youth discussed their songs. For instance, Willi explained that, "Songwriting or writing of any sort is always a good process to work through your own junk." Another songwriter, Robyn, age 18, agreed. She described that she was "going through a lot of depression back in high school" and stated that music was the only thing that helped. She also said that the opportunity to engage in the arts — such as was provided by the \#YouthVoicesWB campaign — could make things for youth "a lot more better, a lot less suicidal, a lot less cutting, a lot less people being in high schools" thinking "why is this so crazy?" Similarly, OG offered his thoughts on how song writing linked specifically to his recovery from the wildfire:

It's a mind clearing, you know, when you can just be chilling; just thinking about random things, and that you all of the sudden end up making art basically. I personally feel if you are touched by the fire that just being able to relax and just put down, write down your thoughts—-that's all. It's 'being' really. So...making music can definitely help somebody who is affected by the wildfire.

As another example, in describing her song Recovery, ${ }^{10}$ Shekinah expressed empathy with those of her peers who had lived through the wildfire disaster, stating that, "even if they didn't have a lot of damage done to their house, they still had to leave. So, it's trying to bring back hope." She makes this connection through her lyrics:

There's something about this town that nobody sees. No matter what tries to bring you down, you can't be beat. And the fire that burnt down all your hopes and dreams. You came back twice as strong ready to take on anything. If I could do something to make this place any better. I would bring back the people that stuck together. Our hearts stayed strong we'll carry on forever. It's all a part of our recovery.

$\overline{10}$ www.thedistrictstudio.ca/youthvoiceswb.html 
As the examples show, creating opportunities for musical expression provides a youth-friendly pathway for supporting youth recovery through songs' creation, sharing, and reception (Davis, 2010; Papinczak et al., 2015). Engaging in arts activities can also foster a sense of belonging for youth, which can support their wellbeing (Bower \& Carroll, 2015). As illustration, Robyn's song Saltwater Kiss ${ }^{11}$ conveys her sense of detachment from community after moving to Fort McMurray soon after the wildfire disaster. Her lyrics speak of her sense of longing for her childhood home in Newfoundland: “To feel the ocean's embrace; oh, saltwater kiss. My heart's rushing with the waves, there's nothing like this. I can always come back, no matter how far I roam. Oh, what I wouldn't do, to go back home." Robyn described

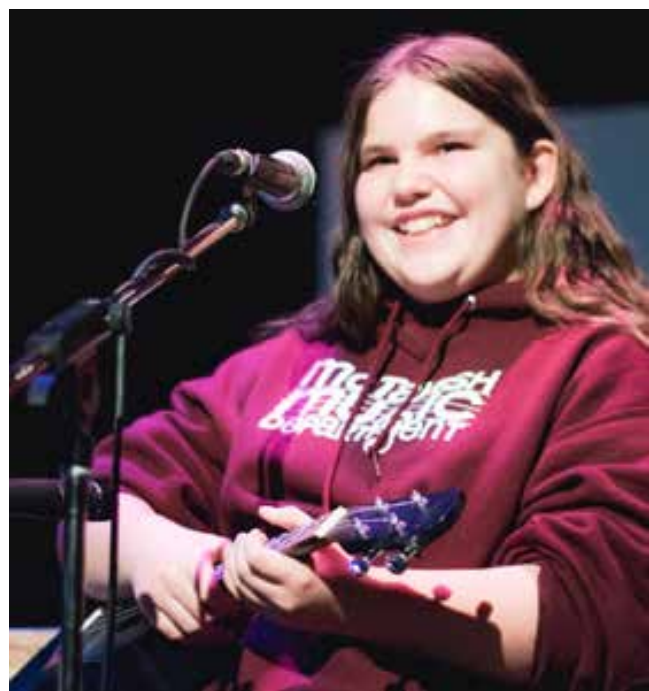

Figure 4. Robyn how one performance sparked a new realization that others may be feeling the same way (see Figure 4). She described how at the \#YouthVoicesWB Talent Showcase a few people came up to her after she performed, stating, "Some of them were like crying; happy with a smile on their face to know that you are actually not the only one who is suffering while I am suffering."

While the act of producing a song alone may not be enough to tackle feeling isolated in a new town, the opportunity to participate in creating the song and performing it at multiple events did offer potential to address this disconnection and support her wellbeing.

\section{Working Through Youth-Adult Partnerships}

As a community-engaged research project, the \#YouthVoicesWB campaign aimed to understand and elevate youth voices through highlighting their priorities for local improvement after the 2016 wildfire disaster. In doing so, multiple local youth-centred organizations across the Wood Buffalo region-and the youth they support-joined the campaign. They did so through developing their own ideas for arts-based activities that fit their organizational mandate, goals, and ways of working (i.e., art installations, graffiti walls, dance, photography, etc.). This approach supported the powerful synergy that can emerge through Youth-Adult Partnerships by prioritizing mentoring models and strengthening community cohesion (Camino, 2000; Zeldin, Christens, \& Powers, 2013).

\footnotetext{
11 www.thedistrictstudio.ca/youthvoiceswb.html
} 


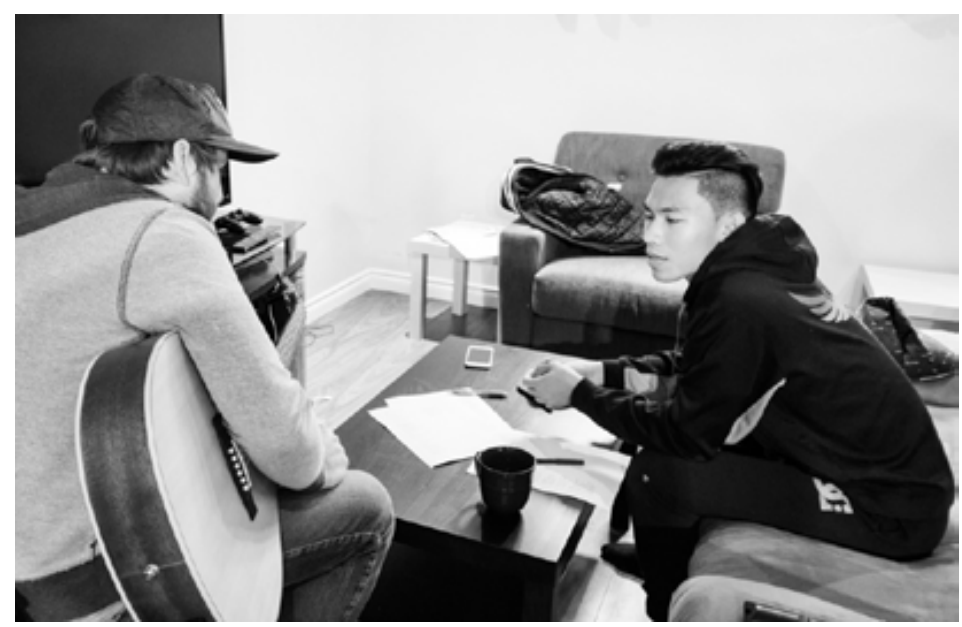

Figure 5. Chris

The songs produced for \#YouthVoiesWB are one example of the Y-AP process. Here, two local organizations, 91.1 The Bridge $\mathrm{FM}^{12}$ and the District Recording Studio, ${ }^{13}$ worked with $\mathrm{RbD}$ Lab researchers to develop a research and arts strategy that reflected their commitment to building youth confidence and enhancing youth wellbeing through music. Together, the two organizations used their networks, social media, and audio-visual production skills to reach local youth ${ }^{14}$ and work with them to professionally produce the seven original songs (see Figure 5).

The organizations shared these songs as part of the \#YouthVoicesWB campaign. They also used the campaign brand to launch interest in a wider initiative called Soundforce Youth ${ }^{15}$ that aims to host youth talent showcase events in the region and support a community of young artists through youth engagement programming. The campaign itself did not create the Soundforce Youth initiative as the project was in development before the wildfire disaster. However, the community-university research partnership allowed youth talent to be showcased in a collective and public way through \#YouthVoicesWB that helped to raise the profile of and interest in the new initiative. Youth and community engagement was fostered through the internet-based campaign and local \#YouthVoicesWB Talent Showcase that profiled the youth's songs in person, online, and on local television. ${ }^{16}$ The process of song creation and community engagement that emerged as part of the \#YouthVoicesWB campaign serves as an example of the potential for community-engaged research partnerships that support not only knowledge generation (Hall, Tandon, \& Tremblay, 2015), but also the sustained engagement and empowerment of young people in the wildfire-affected region.

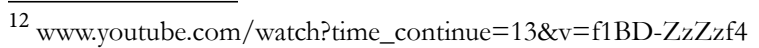

13 www.thedistrictstudio.ca/youthvoiceswb.html

14 www.youtube.com/watch?time_continue $=13 \& v=$ f1BD-ZzZzf4

15 www.thedistrictstudio.ca/soundforce-youth.html

${ }^{16}$ www.youtube.com/playlist?list=PLARu0rgVPBmwEI5AmSxEpc8FDfkwdqDrU
} 
Through the partnership, not only was the act of creating music experienced as beneficial by participating youth, the experience of professionally producing their songs and having an opportunity to perform them publicly was experienced as further validation of the value of their ideas and voices. For instance, Willi was both a song artist in the campaign and one of the primary song producers from the District Recording Studio. He explained the value he saw in his interactions with youth in the studio sessions:

This was really a transformative experience for them... It legitimized that they had a voice in the community and that people cared about what they wanted to say, that they believed that their stories were worth telling. And that is such an advantage to a young person, to any person, but especially a young person.

The youth songwriter Kyler highlighted the relational benefits of having his song shared with others. In a video interview, he described why he was motivated to record Twenty-Sixteen, and how he hopes doing so will inspire other youth to learn from his experiences:

I want to get my voice heard because I got some things to say. I got some stories to tell. And I know that there's a lot of people out there who can relate to what I'm saying. It's [the song] like walking through the lessons I learned, you know... I think most kids that I know can relate to that, so that once they hear it maybe they'll be motivated to come, even to the studio.

Presence and relationships are critical for providing meaningful opportunities for youth engagement. It is often easy to give space for youth voice through invitation, but often harder for youth to come into that space unless they feel safe, and trust that they will be genuinely listened to (Dutta, 2014; Fletcher et al., 2016). As Willi explained:

You make yourself available and nothing happens, it's so easy to be like: 'They don't care! I'm out!' But that's totally not the case. It's like cultivating relationship and showing over time that it's safe for them to talk to you. Being persistent and being always available because then it's the conversation down the road, where it's just a small conversation off to the side where they share something big with you and that's so important. It takes time with any relationship, and we just need to be willing to take the time.

Willi's observation speaks to the value of partnering with local community organizations that have a Y-AP orientation, including the time, commitment, and capacity to create positive, sustained relationships in youth-friendly environments.

\section{Conclusion}

In the context of disaster recovery, the importance of engagement and contributions by youth has been recognized in global frameworks such as the Sendai Framework for Disaster 
Risk Reduction (UNISDR, 2015). As well, the need for greater youth engagement in disaster recovery to support their wellbeing has been identified as an often-missing component for building resilience in the post-disaster environment (Fletcher et al., 2016; Macpherson, Hart, \& Heaver, 2016). Yet connecting to how youth feel, and to their concerns, hopes, and ideas for rebuilding their community is not always a priority as governments, organizations, and individuals focus on rebuilding infrastructure, homes, and services that have been destroyed or damaged during the disaster (Cox et al., 2018). This means youth can often be less visible as a target for recovery activities due to the developmental paradox of their continued dependence on adults and their emerging independence (Cox, Scannell, Heykoop, Tobin-Gurley, \& Peek, 2017). In such an environment, engaging youth in post-disaster decisions requires innovative, creative, and youth-centric strategies by individuals and organizations committed partnering with youth. When given an opportunity to meaningfully contribute their voice to the recovery process and to their community, youth are clear that they have something to say.

The Youth Voices Rising project with its \#YouthVoicesWB campaign offers insight into how community-engaged research, creative arts, and Youth-Adult Partnerships can support this agenda for greater youth wellbeing after a disaster event. It provides examples of the engagement and action opportunities that can be generated through the process of arts creation, production, and sharing. It also shows how such efforts can contribute to the capacity of disaster-affected communities to meaningfully engage youth, legitimize their authentic voice, and work alongside them as active citizens in the recovery process.

\section{About the Authors}

Robin S. Cox is the Director of Royal Roads University's ResiliencebyDesign Lab and a Professor in the MA in Disaster and Emergency Management. Her participatory research is informed by her background in theatre and film, and her commitment to youth engagement and empowerment in disaster risk reduction, social innovation, and climate adaptation.

Tamara Plush (corresponding author) led the Youth Voices Rising project as a Postdoctoral Fellow at Royal Roads University's ResiliencebyDesign Lab. She has a PhD in Communication for Social Change, and has worked extensively in climate change communication and visual storytelling in international development contexts. Her research interests include participatory media, citizen engagement, and responsive listening. Email: tamara.plush@royalroads.ca 


\section{References}

Camino, L. A. (2000). Youth-adult partnerships: Entering new territory in community work and research. Applied Developmental Science, 4(S1), 11-20.

Christens, B. D., \& Peterson, N. A. (2012). The role of empowerment in youth development: A study of sociopolitical control as mediator of ecological systems' influence on developmental outcomes. Journal of Youth and Adolescence, 41(5), 623-635.

Conrad, D., \& Campbell, G. (2008). Participatory research-An empowering methodology with marginalized populations. In P. Liamputtong, \& J. Rumbold (Eds.), Knowing differently: Artsbased and collaborative research methods (pp. 247-263). Hauppauge, NY: Nova Science.

Blanchet-Cohen, N. \& Nelems, R. (2013). A child-centered evaluation of a psychosocial program: Promoting children's healing, safety and well-being in post-disaster context. Children, Youth, \& Environments, 23(1), 23-42.

Barone, T., \& Eisner, E. W. (2011). Arts based research. Thousand Oaks, CA: Sage.

Bower, J. M., \& Carroll, A. (2015). Benefits of getting hooked on sports or the arts: Examining the connectedness of youth who participate in sport and creative arts activities. International Journal of Child and Adolescent Health, 8(2), 169-178.

Cox, R. S., Scannell, L., Heykoop, C., Tobin-Gurley, J., \& Peek, L. (2017). Understanding youth disaster recovery: The vital role of people, places, and activities. International Journal of Disaster Risk Reduction, 22, 249-256.

Cox, R. S., Hill, T. T., Plush, T., Heykoop, C., \& Tremblay, C. (2018). More than a checkbox: engaging youth in disaster risk reduction and resilience in Canada. Natural Hazards, 1-15.

Davis, K. M. (2010). Music and the expressive arts with children experiencing trauma. Journal of Creativity in Mental Health, 5(2), 125-133.

D’Amico, M., Denov, M., Khan, F., Linds, W., \& Akesson, B. (2016). Research as intervention? Exploring the health and well-being of children and youth facing global adversity through participatory visual methods. Global Public Health, 11(5-6), 528-545.

Dutta, M. J. (2014). A culture-centered approach to listening: Voices of social change. International Journal of Listening, 28(2), 67-81.

Elpus, K. (2013). Arts education and positive youth development: Cognitive, behavioral, and social outcomes of adolescents who study the arts. National Endowment for the Arts. Retrieved from https://pdfs.semanticscholar.org/1800/cea040e37d072f58b28a0605447439926104.pdf

Fernandez, G., \& Shaw,R. (2013). Youth council participation in disaster risk reduction in Infanta and Makati, Philippines: A policy review. International Journal of Disaster Risk Science, 4(3), 126-136.

Fletcher, S., Cox, R. S., Scannell, L., Heykoop, C., Tobin-Gurley, J., \& Peek, L. (2016). Youth creating disaster recovery and resilience: A multi-site arts-based youth engagement research project. Children, Youth and Environments, 26(1), 148-163.

Flicker, S., Danforth, J. Y., Wilson, C., Oliver, V., Larkin, J., Restoule, J. P., \& Prentice, T. (2014). "Because we have really unique art": Decolonizing research with Indigenous youth using the arts. International Journal of Indigenous Health, 10(1), 16-34.

Fothergill, A., \& Peek, L. (2015). Children of Katrina. Austin, TX: University of Texas.

Grauenkaer, L., \& Tufte, T. (2018). Youth-led communication for social change: Empowerment, citizen media, and cultures of governance in Northern Ghana. Development in Practice, 28(3), 400-413. 
Haynes, K., \& Tanner, T. M. (2015). Empowering young people and strengthening resilience: Youth-centred participatory video as a tool for climate change adaptation and disaster risk reduction. Children's Geographies, 13(3), 357-371.

Hall, B., Tandon, R., \& Tremblay, C. (2015). Strengthening community university research partnerships: Global perspectives. Victoria, BC and New Delhi, India: University of Victoria and PRIA.

Ho, E., Clarke, A. \& Dougherty, I. (2015). Youth-led social change: Topics, engagement types, organizational types, strategies, and impacts. Futures, 67, 52-62.

Leavy, P. (2015). Method meets art: Arts-based research practice. New York, NY: Guilford Publications.

Malin, H. (2015). Arts participation as a context for youth purpose. Studies in Art Education, 56(3), 268-280.

Macpherson, H., Hart, A., \& Heaver, B. (2016). Building resilience through group visual arts activities: Findings from a scoping study with young people who experience mental health complexities and/or learning difficulties. Journal of Social Work, 16(5), 541-560.

Papinczak, Z. E., Dingle, G. A., Stoyanov, S. R., Hides, L., \& Zelenko, O. (2015). Young people's uses of music for wellbeing. Journal of Youth Studies, 18(9), 1119-1134.

Peek, L., Abramson, D.M., Cox, R.S., Fothergill, A., \& Tobin J. (2018). Children and Disasters. In H. Rodríguez, W. Donner, J. Trainor (Eds.), Handbook of Disaster Research: Handbooks of Sociology and Social Research. New York, NY: Springer.

Peek, L., Tobin-Gurley, J., Cox, R. S., Scannell, L., Fletcher, S., \& Heykoop, C. (2016). Engaging youth in post-disaster research: Lessons learned from a creative methods approach. Gateways: International Journal of Community Research and Engagement, 9(1), 89-112.

Plush, T. (2016). We've raised their voice. Is anyone listening? Participatory video practitioners and valued citizen voice in international development contexts (Doctorial dissertation), Retrieved from University of Queensland eSpace database. https://espace.library.uq.edu.au/view/ UQ:398615.

Plush, T. (2015). Participatory video and citizen voice - We've raised their voices: Is anyone listening? Glocal Times, 22/23, 1-16.

Powell, T., \& Holleran-Steiker, L. K. (2017). Supporting children after a disaster: A case study of a psychosocial school-based intervention. Clinical Social Work Journal, 45(2), 176-188.

ResiliencebyDesign Lab (2018). Youth Vision \& Voice in Wood Buffalo. Victoria, BC: Royal Roads University. Retrieved from www.resiliencebydesign.com/youthvoiceswb

Seballos, F., \& Tanner, T. (2011). Enabling Child-Centred Agency in Disaster Risk Reduction. Global Assessment Report on Disaster Risk Reduction. Geneva, Switzerland: UNISDR.

UNISDR (2015). Sendai Framework for Disaster Risk Reduction 2015-2030. United Nations Office for Disaster Risk Reduction. Retrieved from www.unisdr.org/we/coordinate/sendaiframework

Ungar, M. (2012). The social ecology of resilience: A bandbook of theory and practice. New York, NY: Springer.

Walls, A., Deane, K., \& O'Connor, P. (2016). 'Looking for the blue, the yellow, all the colours of the rainbow': The value of participatory arts for young people in social work practice. Aotearoa New Zealand Social Work, 28(4), 67-79.

Wheatley, B., \& Bickerton, C. (2017). Subjective well-being and engagement in arts, culture and sports. Journal of Cultural Economics, 41(1), 23-45.

Zeldin, S., Christens, B. D., \& Powers, J. L. (2013). The psychology and practice of youth-adult partnership: bridging generations for youth development and community change. American Journal of Community Psychology, 51(3-4), 385-397.

Engaged Scholar Journal: Community-Engaged Research, Teaching, and Learning 